\title{
RANCANG BANGUN PENGENALAN LOKASI WISATA KOTA SEMARANG DENGAN MENERAPKAN TEKNOLOGI REALITAS TERTAMBAH MENGGUNAKAN UNITY DAN VUFORIA
}

\author{
Radhitya Wiratama*), Maman Somantri, dan Yuli Christyono \\ Departemen Teknik Elektro, Universitas Diponegoro \\ Jl. Prof. Sudharto, SH, Kampus UNDIP Tembalang, Semarang 50275, Indonesia \\ ${ }^{*}$ E-mail: radhityawiratama@gmail.com
}

\begin{abstract}
Abstrak
Semarang merupakan ibukota Jawa Tengah yang memiliki sejarah yang erat kaitannya dengan sejarah Republik Indonesia pada zaman penjajahan Belanda. Kota semarang memiliki beberapa objek wisata dan bangunan bersejarah, namun beberapa dari objek wisata tidak menyediakan informasi mengenai sejarah dan cerita dari objek wisata tersebut. Pada zaman yang serba digital seperti sekarang ini, perlu adanya teknologi yang memudahkan calon pengunjung objek wisata untuk melihat informasi wisata. Teknologi realitas tertambah yang berbasis Android dapat digunakan sebagai pendekatan untuk membuat aplikasi yang berisi informasi objek wisata lebih menarik dan informatif. Aplikasi ini nantinya dapat melakukan pemindaian marker dan menghasilkan objek berupa bentuk bangunan objek wisata dalam bentuk tiga dimensi (3D), suara narasi, dan tombol untuk menunjukkan letak lokasi wisata. Aplikasi ini dibangun dengan menggunakan Unity 3D untuk membangun tampilan antarmuka, dan Vuforia sebagai engine untuk menganalisis marker dan memunculkan fitur realitas tertambah. Fitur lokasi pada aplikasi ini digunakan tombol sebagai hasil pemindaian untuk menampilkan lokasi wisata pada Google Maps. Pengujian yang dilakukan pada aplikasi ini yaitu pengujian dari segi tampilan antarmuka dan fitur realitas tertambah. Hasil dari perancangan ini yaitu aplikasi berhasil melakukan pemindaian terhadap marker dan menghasilkan objek bangunan 3D, tombol untuk menampilkan lokasi wisata, dan suara narasi yang menjelaskan informasi singkat mengenai objek wisata.
\end{abstract}

Kata Kunci: Realitas tertambah, Android, marker, Vuforia, Unity 3D

\begin{abstract}
Semarang is a capital city of Central Java province which it has history related to the history of the Republic of Indonesia during the Dutch colonial era. Semarang has some tourism landmarks and historical buildings, but some of them does not provide information or historical story. In digital era, there needs a technology to ease tourist for looking an information to a landmark or historical building. An Android based augmented reality technology can be used as an approach to make an application that contain tourist information more interesting and informative. This application will be built using Unity 3D as game engine to build an user interface, and Vuforia to add an augmented reality feature and analyze some markers. Map feature will be added in this application to show location of landmarks or historical building by using a button as result of scanning a marker. That button will open the Google Maps and show the location of landmark. Some tests has done on this application, the tests are in terms of interface display and augmented reality feature. This application will scan a marker that can produce a three-dimension (3D) object of tourism landmark, narration voice, and a button that show location of tourism landmark. The result of this software development is this application can scan a marker which it show a 3D object, a narration voice, and a button.
\end{abstract}

Key word: Augmented Reality, Android, marker, Vuforia, Unity 3D.

\section{Pendahuluan}

Semarang merupakan ibukota Jawa Tengah yang memiliki sejarah yang erat kaitannya dengan sejarah Republik Indonesia pada zaman penjajahan Belanda. Sejarahnya yang panjang menjadikan Kota Semarang salah satu kota yang bersejarah di Jawa Tengah pada khususnya dan di Indonesia pada umumnya.

Nilai historis dan makna dari perjuangan bangsa Indonesia yang terkandung pada sebuah bangunan bersejarah haruslah diketahui oleh setiap pengunjungnya. Hal itulah yang membuat suatu bangunan bersejarah dapat menjadi objek wisata yang menarik dan juga 
edukatif serta dapat menyalurkan semangat juang bagi siapapun yang mengunjunginya. Nilai historis suatu bangunan dapat dilihat dari segi fisik bangunan dan informasi sejarah terbentuknya bangunan tersebut. Informasi mengenai fungsi bangunan tersebut dari masa ke masa juga akan menambah nilai sejarah situs bersejarah. Oleh karena itu, pada penyampaian informasi sejarah suatu objek wisata bersejarah janganlah sampai ada kesalahan atau kesimpang-siuran informasi.

Sayangnya, beberapa lokasi wisata menyediakan informasi yang minin mengenai sejarah, fasilitas, lokasi, ataupun informasi lainnya mengenai lokasi wisata tersebut. Informasi yang disediakan melalui internet pun ada beberapa yang tidak menyertakan gambar detail mengenai lokasi tempat wisata yang dimaksud.

Maka dari itu, perlu adanya suatu pendekatan teknologi untuk mengatasi kesimpang-siuran mengenai informasi mengenai objek wisata. Selain itu, pendekatan teknologi juga dilakukan untuk melengkapi informasi wisata agar lebih menarik untuk dilihat oleh pengunjung.

Salah satu teknologi yang sedang hangat saat ini yaitu realitas tertambah atau yang populer dengan istilah Augmented Reality (AR), yaitu teknologi yang memungkinkan manusia melihat benda yang berwujud tak nyata atau virtual di dunia nyata dengan bantuan kamera telepon genggam. Penelitian mengenai realitas tertambah telah banyak dilakukan untuk berbagai kegunaan. Misalnya pada penelitian yang dilakukan oleh Feri Ardiyansyah [1] yang menerapkan realitas tertambah sebagai pengenalan monumen bersejarah di Kota Bandung dengan menggunakan video dan teks sebagai hasil dari pemindaian. Kemudian, perancangan realitas tertambah untuk diimplementasikan di museum yang dilakukan oleh Aditya Rizki dkk yang menghasilkan objek tiga dimensi (3D) sebagai hasil pemindaian [2]. Tidak hanya pada monumen dan museum, realitas tertambah juga dapat diimplementasikan sebagai media informasi kampus pada penelitian yang dilakukan oleh Latius Hermawan dan Mochamad Hariadi dengan menggunakan Unity dan Vuforia [3]. Teknologi realitas tertambah juga dapat diterapkan pada bidang properti dan pemasaran perumahan, seperti pada penelitian yang dilakukan oleh Muhammad Rifa'i dkk yang juga menggunakan Unity dan Vuforia, serta menampilkan objek 3D sebagai hasil pemindaian [4]. Penelitian mengenai teknologi realitas tertambah yang dapat diimplementasikan untuk mengetahui fasilitas umum dilakukan oleh Fadilah dan Yuliana dengan menggunakan Google Maps sebagai hasil dari realitas tertambah [5].

Hasil penerapan teknologi AR cukup menarik karena pengguna dapat melihat objek virtual dalam bentuk nyata, yaitu grafis tiga dimensi (3D) sehingga seolah-olah objek tersebut berada di dunia nyata dengan bantuan kamera telepon genggam yang berbasis sistem operasi Android.
Teknologi AR sekarang ini sedang populer karena fiturnya yang menarik, bahkan beberapa permainan dan aplikasi menggunakan teknologi ini. Sedangkan Android merupakan sistem operasi telepon genggam dengan pengguna terbanyak di Indonesia.

\section{Metode \\ 2.1. Sistem Operasi Android}

Android merupakan sebuah sistem operasi yang berbasis Linux untuk telepon seluler seperti telepon pintar dan komputer tablet. Android menyediakan platform terbuka bagi para pengembang untuk menciptakan aplikasi mereka sendiri untuk digunakan oleh bermacam peranti bergerak [6].

\subsection{Unity 3D}

Unity 3D merupakan sebuah perangkat lunak pemrograman yang digunakan untuk membuat berbagai macam aplikasi. Walaupun mayoritas penggunaan Unity 3D untuk pembuatan aplikasi berupa game, namun Unity 3D juga dapat membuat aplikasi untuk kegunaan lain, misalnya koneksi dengan MySQL dan menambah fitur Realitas Tertambah [7].

\subsection{Vuforia}

Vuforia merupakan perangkat lunak pengembang untuk realitas tertambah (Augmented Reality Software Development Kit atau SDK) untuk perangkat mobile yang memungkinkan pembuatan aplikasi dengan menggunakan teknologi realitas tertambah. Vuforia merupakan SDK yang disediakan oleh Qualcomm untuk membantu para pengembang membuat aplikasi-aplikasi realitas tertambah pada perangkat telepon genggam (iOS, Android). SDK Vuforia sudah sukses dipakai di beberapa aplikasiaplikasi mobile untuk kedua platform tersebut [3].

\subsection{Realitas Tertambah}

Realitas tertambah, atau dikenal dengan istilah Augmented Reality (AR), adalah teknologi yang menggabungkan benda maya dua dimensi dan ataupun tiga dimensi ke dalam sebuah lingkungan nyata tiga dimensi lalu memproyeksikan benda-benda maya tersebut dalam waktu nyata. Tidak seperti realitas maya (Virtual Reality atau VR) yang sepenuhnya menggantikan kenyataan, realitas tertambah sekedar menambahkan atau melengkapi kenyataan [8].

\subsection{Bahasa Pemograman C\#}

Bahasa pemograman C\#, merupakan bahasa pemograman buatan Microsoft yang berjalan pada platform .NET. C\# diluncurkan pada tahun 2000 dan dikembangkan oleh tim yang dipimpin oleh Anders Hejlsberg dan Scott Wiltamuth. C\# memiliki kesamaan bahasa dengan bahasa 
pemograman $\mathrm{C}, \mathrm{C}++$, dan Java, sehingga memudahkan pengembang perangkat lunak yang telah terbiasa menggunakan bahasa $\mathrm{C}$ untuk menggunakan bahasa pemograman C\#. Bahasa pemograman ini merupakan bahasa pemograman yang berorientasi objek (object oriented programming) dan memiliki class library yang berisi prebuilt component, sehingga memudahkan programmer untuk membuat dan mengembangkan perangkat lunak lebih cepat [9].

\subsection{Analisa Kebutuhan}

Beberapa kebutuhan fungsional yang disediakan oleh aplikasi Semarang Guide 3D adalah sebagai berikut:

1. Memungkinkan pengguna untuk memindai marker yang telah disediakan dengan menggunakan kamera ponsel.

2. Menampilkan gambar 3D, suara, dan lokasi sebagai hasil dari pemindaian

3. Menampilkan sejarah dan informasi lainnya mengenai beberapa tempat wisata.

Adapun kebutuhan non-fungsional yang disediakan oleh aplikasi ini adalah sebagai berikut:

1. Waktu tunda dimulai dari proses pemindaian marker hingga menampilkan hasil yang berlangsung singkat.

2. Meminimalisir pemakaian koneksi internet.

\subsection{Unified Modeling Language (UML)}

\subsubsection{Diagram Use Case}

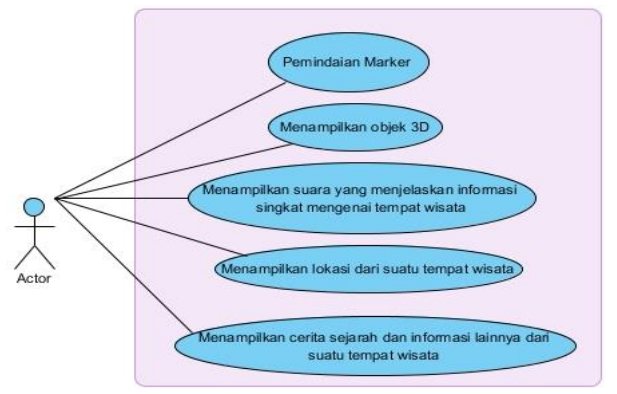

Gambar 1. Diagram Use Case Aplikasi Semarang Guide 3D

Gambar 1 di atas menunjukkan diagram use case pada aplikasi Semarang Guide 3D. Diagram use case menunjukkan beberapa fitur dan kegunaan aplikasi, antara lain:

1. Dapat memindai marker AR sehingga dapat menampilkan hasil berupa objek gambar 3D yang disertai suara yang menjelaskan informasi mengenai suatu objek wisata serta lokasi objek wisata.

2. Menampilkan cerita sejarah dan informasi lainnya mengenai suatu objek wisata.

\subsubsection{Diagram Aktivitas}

Pada Gambar 2 dapat dilihat bahwa apabila menu "pindai" dipilih, maka aplikasi akan membuka aplikasi kamera yang digunakan untuk memindai marker. Hasil dari pemindaian marker yaitu berupa objek 3D, suara narasi, dan tombol "Tampilkan Lokasi". Apabila tombol "Tampilkan Lokasi" ditekan, maka aplikasi akan membuka Google Maps dan menampilkan lokasi dari objek pada marker yang dipindai.

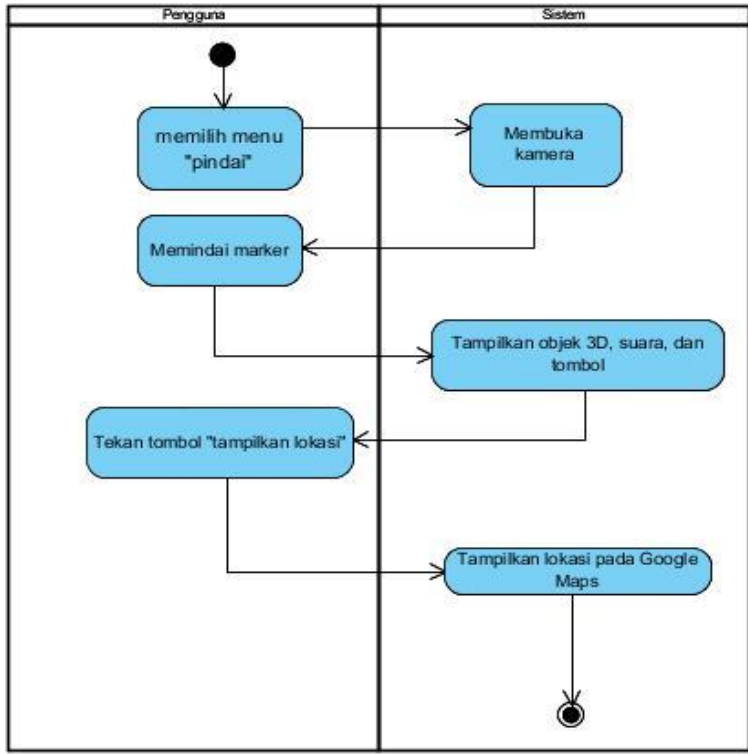

Gambar 2. Diagram Aktivitas Pemindaian

\subsection{Diagram Alir AR}

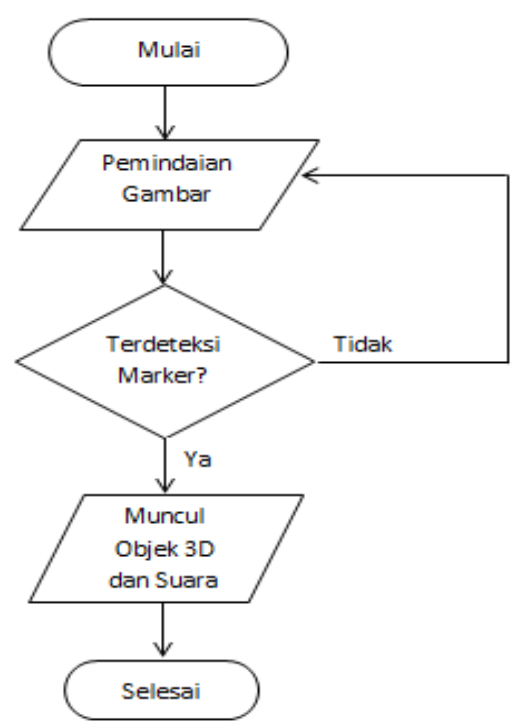

Gambar 3. Diagram Alir Pemindaian Gambar

Pada Gambar 3 di atas dapat dilihat diagram alir yang menjelaskan alur kerja pemindaian gambar pada aplikasi Semarang Guide 3D . Proses akan dimulai ketika 
pengguna memilih menu "Pindai" lalu "Pindai Gambar" pada antarmuka. Kemudian, aplikasi kamera akan terbuka untuk memindai marker. Apabila kamera mendeteksi adanya marker yang sesuai, maka objek 3D dari marker yang dipindai akan muncul pada layar, bersamaan dengan terdengarnya suara narasi informasi dari marker yang dipindai. Apabila kamera tidak mendeteksi adanya marker, maka tidak terjadi apa-apa dan proses pemindaian marker masih berjalan hingga kamera mendeteksi adanya marker yang sesuai.

Proses akan berakhir apabila pengguna menekan tombol "kembali" dan akan kembali ke tampilan antarmuka.

\section{Hasil dan Analisa \\ 3.1. Antarmuka Pengguna}

Pada antarmuka aplikasi Semarang Guide 3D, terdapat lima buah tombol menu yang berada di bagian bawah layar. Tiap tombol menu ini akan tampil pada setiap menu yang dipilih. Namun, pada beberapa tampilan seperti tampilan informasi pada setiap objek wisata, tampilan bantuan, menu pemindaian, dan tampilan tentang aplikasi, baris tombol menu pada bagian bawah tidak akan tampak. Namun agar pengguna dapat kembali ke layar sebelumnya, disediakan tombol kembali.

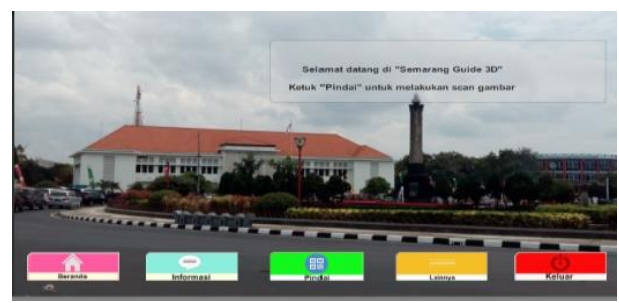

\section{Gambar 4. Tampilan Beranda}

Pada Gambar 4 di atas terlihat tampilan Beranda. Beranda selalu ditampilkan sebagai inisialisasi ketika aplikasi Semarang Guide 3D dibuka. Pada tampilan Beranda, terdapat ucapan "Selamat Datang" kepada pengguna dan panduan singkat untuk melakukan pemindaian.

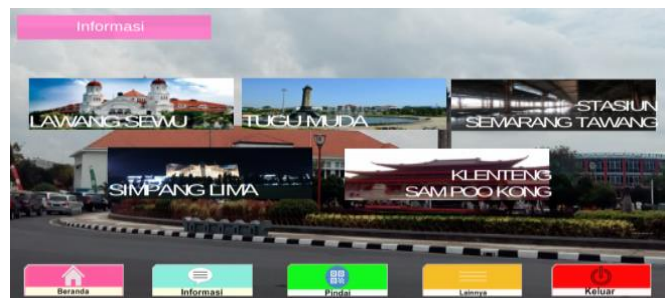

\section{Gambar 5. Tampilan Menu Informasi}

Gambar 5 di atas menunjukkan tampilan menu informasi. Pada tampilan menu informasi, tersedia lima buah tombol menu yang mewakili informasi tiap objek wisata atau objek bangunan bersejarah. Pada menu ini, pengguna hanya perlu menyentuh salah satu tombol pilihan informasi objek wisata untuk dilihat informasinya.

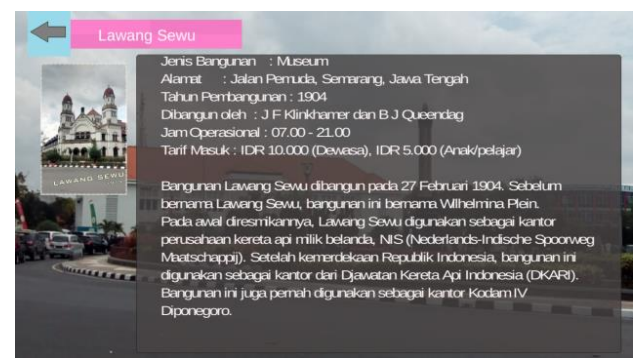

\section{Gambar 6. Tampilan Informasi}

Gambar 6 di atas merupakan tampilan informasi Lawang Sewu. Tampilan ini akan muncul apabila pada menu informasi, tombol Lawang Sewu disentuh atau diketuk. Untuk kembali ke menu informasi, pengguna dapat menyentuh atau mengetuk tombol kembali yang berada di pojok kiri atas layar. Tampilan yang serupa akan tampil pada tampilan informasi Tugu Muda, Sam Poo Kong, Simpang Lima, dan Stasiun Tawang.

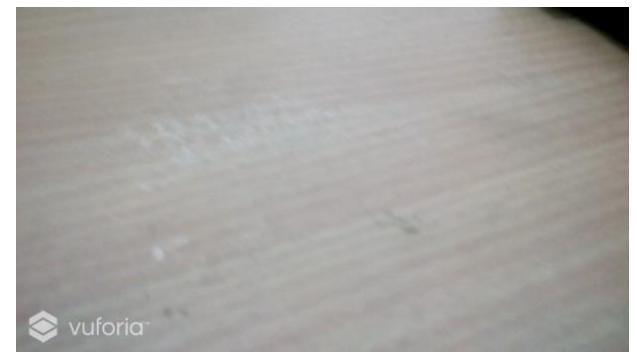

\section{Gambar 7. Tampilan Jika Menu Pindai Dipilih}

Gambar 7 di atas merupakan tampilan apabila menu Pindai disentuh atau diketuk. Sesuai dengan pada saat perancangan, apabila menu Pindai disentuh atau diketuk, maka sistem akan membuka AR Camera yang akan memindai marker.

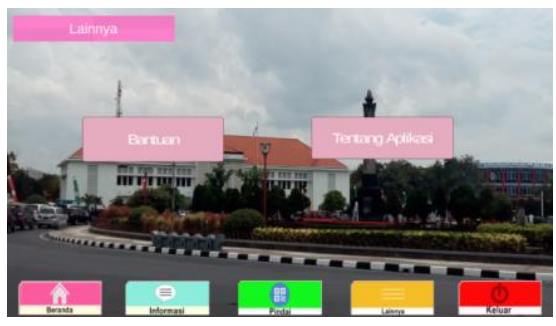

Gambar 8. Tampilan Menu Lainnya

Gambar 8 menunjukkan tampilan menu Lainnya. Pada Menu ini tersedia dua buah submenu, yaitu submenu Bantuan dan submenuTentang Aplikasi. Submenu Bantuan berisi cara penggunaan aplikasi Semarang Guide $3 D$, sedangkan submenu Tentang Aplikasi berisi deskripsi dan versi aplikasi. 


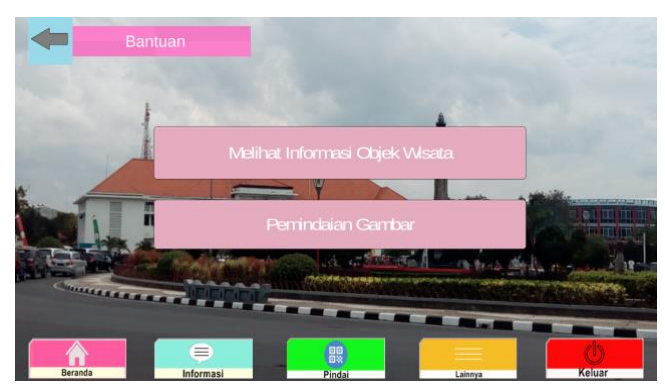

Gambar 9. Tampilan Submenu Bantuan

Gambar 9 menunjukkan tampilan submenu Bantuan. Submenu Bantuan akan tampil apabila tombol Bantuan diketuk atau disentuh. Pada subemnu Bantuan, terdapat dua buah submenu yang menampilkan kategori bantuan, yaitu bantuan untuk melihat informasi wisata dan bantuan untuk pemindaian.

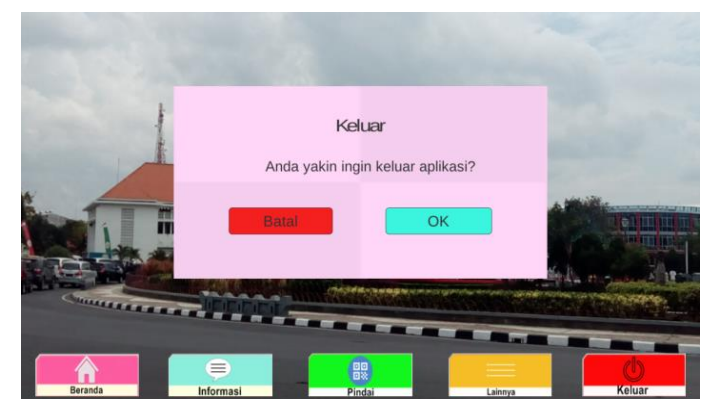

Gambar 10. Tampilan Menu Keluar

Pada Gambar 10 di atas dapat dilihat tampilan menu Keluar. Agar tidak terjadi keluar aplikasi secara tidak sengaja, maka ketika tombol Keluar disentuh maka akan muncul konfirmasi untuk keluar. Jika pengguna menyentuh OK, maka aplikasi akan menutup. Sedangkan apabila pengguna menyentuh Batal, maka tampilan akan kembali ke Beranda.

\subsection{Pengujian AR \\ 3.2.1. Pengujian Kemunculan Objek}

Fitur utama dari aplikasi Semarang Guide 3D yaitu menampilkan objek 3D, suara, dan tombol yang menunjukkan lokasi objek wisata pada saat melakukan pemindaian pada marker. Aspek pengujian yang paling utama adalah kemunculan objek, yaitu untuk menguji apakah sistem dapat memunculkan objek AR saat pemindaian. Pengujian dilakukan pada lima buah marker yang mewakili masing-masing objek wisata, yaitu Lawang Sewu, Tugu Muda, Simpang Lima, Stasiun Tawang, dan Sam Poo Kong.

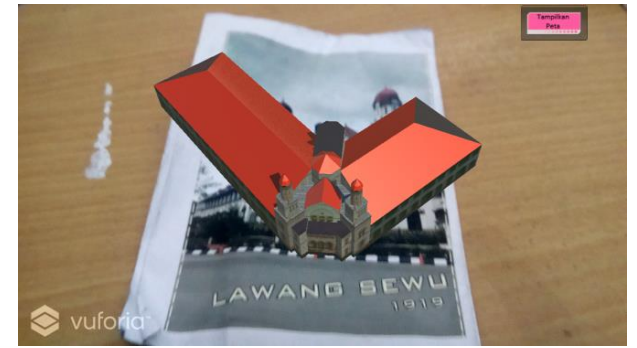

Gambar 11. Tampilan Objek Lawang Sewu

Pada Gambar 11 di atas dapat dilihat bahwa ketika melakukan pemindaian terhadap marker Lawang Sewu, maka akan muncul objek berupa bangunan Lawang Sewu berbentuk 3D dan tombol. Pada kondisi sebenarnya, hasil pemindaian juga mengeluarkan suara. Hal ini menunjukkan bahwa pemindaian untuk marker Lawang Sewu berhasil dan sesuai dengan yang diharapkan pada bagian perancangan. Hasil yang serupa juga dihasilkan saat memindai marker Stasiun Tawang, Simpang Lima, Sam Poo Kong, dan Tugu Muda.

Tabel 1 Hasil Pengujian Kemunculan Komponen AR

\begin{tabular}{|c|c|c|c|c|}
\hline No & Objek & Objek 3D & Tombol & Suara \\
\hline 1 & $\begin{array}{c}\text { Lawang } \\
\text { Sewu }\end{array}$ & Muncul & Muncul & Muncul \\
\hline 2 & Tugu Muda & Muncul & Muncul & Muncul \\
\hline 3 & $\begin{array}{c}\text { Simpang } \\
\text { Lima }\end{array}$ & Muncul & Muncul & Muncul \\
\hline 4 & $\begin{array}{l}\text { Stasiun } \\
\text { Tawang }\end{array}$ & Muncul & Muncul & Muncul \\
\hline 5 & $\begin{array}{c}\text { Sam Poo } \\
\text { Kong }\end{array}$ & Muncul & Muncul & Muncul \\
\hline
\end{tabular}

Pada Tabel 1 dapat dilihat bahwa dari semua objek atau marker yang dipindai, menghasilkan ketiga objek AR yang berupa objek 3D, tombol untuk menampilkan lokasi, dan suara narasi dari marker yang dipindai. Hal ini telah sesuai dengan hasil yang diharapkan pada saat perancangan, yaitu pada saat melakukan pemindaian pada setiap marker, akan menghasilkan komponen AR berupa objek bangunan 3D, tombol, dan suara.

\subsubsection{Tombol Tampilkan Lokasi}

Pengujian tombol "Tampilkan Lokasi" dilakukan untuk menguji apakah tombol dapat berfungsi dengan baik, yaitu dengan membuka Google Maps dan menunjukkan lokasi sesuai dengan marker yang dipindai.

Pada gambar 12 di atas dapat dilihat tampilan Google Maps yang menunjukkan lokasi Lawang Sewu. Tampilan tersebut akan muncul saat tombol Tampilkan Lokasi yang muncul saat pemindaian marker Lawang Sewu disentuh. Hal ini menunjukkan bahwa tombol Tampilkan Lokasi untuk marker Lawang Sewu telah berfungsi dengan baik. Hasil serupa juga dihasilkan pada pemindaian marker 
Stasiun Tawang, Simpang Lima, Sam Poo Kong, dan Tugu Muda.

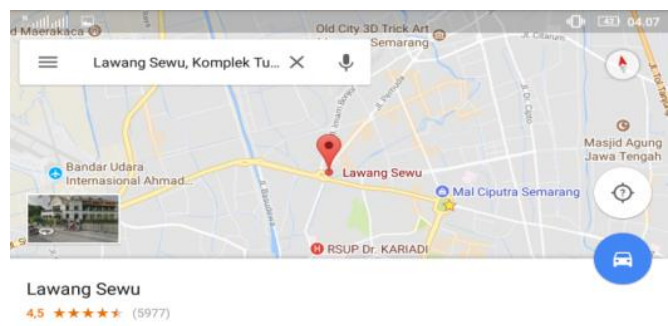

Gambar 12. Lokasi Lawang Sewu

\subsubsection{Pengujian Sudut}

Tabel 2. Hasil Pengujian Sudut

\begin{tabular}{|c|c|c|c|c|c|c|}
\hline \multirow{2}{*}{ No } & \multirow{2}{*}{ Objek } & \multicolumn{4}{|c|}{ Hasil Pengujian } & \multirow{2}{*}{$\begin{array}{c}\text { Sudut } \\
\text { Minimal }\end{array}$} \\
\hline & & $90^{\circ}$ & $45^{\circ}$ & $10^{\circ}$ & $0^{\circ}$ & \\
\hline 1 & $\begin{array}{l}\text { Lawang } \\
\text { Sewu }\end{array}$ & $\sqrt{ }$ & $\sqrt{ }$ & $\sqrt{ }$ & $x$ & $10^{\circ}$ \\
\hline 2 & Tugu Muda & $\sqrt{ }$ & $\sqrt{ }$ & $x$ & $x$ & $30^{\circ}$ \\
\hline 3 & $\begin{array}{l}\text { Simpang } \\
\text { Lima }\end{array}$ & $\sqrt{ }$ & $\sqrt{ }$ & $\sqrt{ }$ & $x$ & $10^{\circ}$ \\
\hline 4 & $\begin{array}{l}\text { Stasiun } \\
\text { Tawang }\end{array}$ & $\sqrt{ }$ & $\sqrt{ }$ & $x$ & $x$ & $20^{\circ}$ \\
\hline 5 & $\begin{array}{l}\text { Sam Poo } \\
\text { Kong }\end{array}$ & $\sqrt{ }$ & $\sqrt{ }$ & $x$ & $x$ & $30^{\circ}$ \\
\hline
\end{tabular}

Berdasarkan hasil pengujian pada Tabel 2, dapat dilihat bahwa semua marker dapat terdeteksi hingga sudut $45^{\circ}$, sedangkan untuk marker Lawang Sewu dan Simpang Lima dapat terdeteksi hingga kemiringan $10^{\circ}$. Untuk kemiringan $0^{\circ}$ kamera tidak dapat mendeteksi adanya marker. Adanya perbedaan sudut minimal untuk mendeteksi adanya marker untuk setiap marker disebabkan kualitas gambar pada marker yang terlalu gelap. Sudut $90^{\circ}$ pada pengujian ini tegak lurus atau tepat diatas marker.

\subsubsection{Pengujian Jarak}

Tabel 3 Hasil Pengujian Jarak

\begin{tabular}{llrr}
\hline No & \multicolumn{1}{c}{ Objek } & $\begin{array}{c}\text { Jarak Terdekat } \\
(\mathbf{c m})\end{array}$ & $\begin{array}{c}\text { Jarak Terjauh } \\
\text { (cm) }\end{array}$ \\
\hline 1 & Lawang Sewu & 10 & 162 \\
2 & Tugu Muda & 10 & 139 \\
3 & Simpang Lima & 11 & 91 \\
4 & Stasiun Tawang & 17 & 156 \\
5 & Sam Poo Kong & 17 & 89 \\
\hline
\end{tabular}

Berdasarkan hasil pengujian pada Tabel 3, dapat dilihat bahwa jarak terdekat kamera untuk mendeteksi marker yaitu $10 \mathrm{~cm}$ untuk marker Lawang Sewu dan Tugu Muda. Sedangkan jarak terjauh kamera untuk mendeteksi marker yaitu $162 \mathrm{~cm}$ untuk marker Lawang Sewu. Untuk marker Sam Poo Kong memiliki jarak deteksi terjauh paling kecil diantara marker lainnya, yaitu hanya $89 \mathrm{~cm}$. lebih dari jarak tersebut, kamera sudah tidak dapat mendeteksi adanya marker. Adanya perbedaan jarak deteksi ini disebabkan oleh kualitas marker yang sudah diukur pada situs Vuforia. Pada situs Vuforia, Sam Poo Kong mendapatkan kualitas marker dengan rating 4 dari 5 yang menandakan bahwa kualitas marker cukup dan tidak dapat melakukan pemindaian dengan jarak yang jauh.

\subsubsection{Pengujian Waktu Pindai}

\section{Tabel 4 Hasil Pengujian Waktu Pemindaian}

\begin{tabular}{|c|c|c|c|c|c|c|c|}
\hline \multirow{3}{*}{ No } & \multirow{3}{*}{ Marker } & \multicolumn{6}{|c|}{ Waktu Proses (detik) } \\
\hline & & \multicolumn{5}{|c|}{ Pengujian Ke- } & \multirow{2}{*}{$\begin{array}{l}\text { Rata- } \\
\text { rata }\end{array}$} \\
\hline & & 1 & 2 & 3 & 4 & 5 & \\
\hline 1 & $\begin{array}{l}\text { Lawang } \\
\text { Sewu }\end{array}$ & 1,06 & 1,20 & 1,80 & 1,12 & 0,82 & 1,20 \\
\hline 2 & Tugu Muda & 1,38 & 1,57 & 1,70 & 0,71 & 1,80 & 1,43 \\
\hline 3 & $\begin{array}{l}\text { Simpang } \\
\text { Lima }\end{array}$ & 1,48 & 1,38 & 1,50 & 1,45 & 1,10 & 1,38 \\
\hline 4 & $\begin{array}{l}\text { Stasiun } \\
\text { Tawang }\end{array}$ & 2,01 & 1,30 & 1,39 & 1,34 & 1,20 & 1,44 \\
\hline 5 & $\begin{array}{l}\text { Sam Poo } \\
\text { Kong }\end{array}$ & 1,90 & 1,53 & 1,39 & 1,51 & 1,57 & 1,58 \\
\hline
\end{tabular}

Berdasarkan hasil pengujian lama waktu pemindaian yang terdapat pada Tabel 4, dapat dilihat bahwa waktu pemindaian tercepat yaitu pada saat sistem memindai marker Lawang Sewu, dengan waktu rata-rata selama 1,20 detik. Sedangkan waktu pemindaian terlama yaitu pada saat sistem memindai marker Sam Poo Kong dengan waktu rata-rata selama 1,58 detik. Perbedaan waktu pemindaian dapat disebabkan oleh kualitas marker dan ukuran data objek 3D yang ditampilkan.

\subsubsection{Uji Fungsionalitas}

Tabel 5 Hasil Pengujian Fungsionalitas

\begin{tabular}{cllll}
\hline No & \multicolumn{1}{c}{ Objek } & Diperbesar & Diperkecil & Diputar \\
\hline 1 & Lawang Sewu & Berhasil & Berhasil & Berhasil \\
2 & Tugu Muda & Berhasil & Berhasil & Berhasil \\
3 & Simpang Lima & Berhasil & Berhasil & Berhasil \\
4 & Stasiun Tawang & Berhasil & Berhasil & Berhasil \\
5 & Sam Poo Kong & Berhasil & Berhasil & Berhasil \\
\hline
\end{tabular}

Dari data hasil pengujian pada Tabel 5, dapat dilihat bahwa semua objek 3D memiliki semua fitur yang diharapkan, yaitu dapat diperbesar, diperkecil, dan diputar. Hal ini sudah sesuai dengan perancangan.

\subsubsection{Uji Perubahan Warna Marker}

Pengujian perubahan warna pada marker bertujuan untuk mengetahui apakah kamera masih mendeteksi adanya marker yang sesuai apabila marker dilakukan perubahan warna. Perubahan warna yang dilakukan pada marker yaitu dengan cara mengubah warna menjadi aras keabuan (greyscale) dan hitam putih. Pengujian dilakukan pada tingkat kecerahan yang sama.

Dari data hasil pengujian pada Tabel 6, dapat dilihat bahwa semua marker yang diubah warnanya menjadi aras 
keabuan dapat terdeteksi oleh kamera dan menghasilkan komponen AR berupa suara, objek 3D, dan tombol untuk menampilkan lokasi. Tidak semua marker yang diubah warnanya menjadi hitam-putih dapat terdeteksi oleh kamera dan menghasilkan komponen AR. Marker Sam Poo Kong berwarna hitam-putih sulit terdeteksi oleh kamera, sehingga komponen AR membutuhkan proses yang lebih lama untuk ditampilkan atau komponen AR dapat tampil namun tak lama hilang ketika pemindaian masih berlangsung.

Tabel 6. Hasil Uji Perubahan Warna Marker

\begin{tabular}{clll}
\hline \multirow{2}{*}{ No } & \multirow{2}{*}{ Marker } & \multicolumn{2}{c}{ Hasil Pemindaian } \\
\cline { 3 - 4 } & & Aras Keabuan & Hitam-putih \\
\hline 1 & Lawang Sewu & Berhasil & Berhasil \\
2 & Tugu Muda & Berhasil & Berhasil \\
3 & Simpang Lima & Berhasil & Berhasil \\
4 & Stasiun Tawang & Berhasil & Berhasil \\
5 & Sam Poo Kong & Berhasil & Sulit \\
& & & terdeteksi \\
\hline
\end{tabular}

\section{Kesimpulan}

Dari beberapa pengujian yang telah dilakukan, maka dapat disimpulkan bahwa tombol pada antarmuka sudah berfungsi dengan baik dan sesuai dengan perancangan pada UML. Fitur Realitas Tertambah atau AR juga dapat berfungsi dengan baik untuk setiap marker. Hal ini ditandai dengan munculnya semua komponen AR berupa suara, objek 3D, dan tombol untuk menampilkan lokasi pada saat pemindaian. Aplikasi ini dapat dikembangkan dengan menambah informasi terbaru mengenai pariwisata di Kota Semarang dan informasi angkutan Bus Rapid Transit (BRT) menuju dan dari lokasi wisata tertentu.

\section{Referensi}

[1] Feri Ardiyansyah, "Implementasi Pattern Recognition Pada Pengenalan Monumen-Monumen Bersejarah di Kota Bandung Menggunakan Augmented Reality Berbasis Android", Jurnal Ilmiah Komputer dan Informatika (KOMPUTA), Vol. 1, No. 1, hal 1-8, Agt, 2014.

[2] Aditya Rizki dkk, "Implementasi Augmented Reality di Museum: Studi Awal Perancangan Aplikasi Edukasi Untuk Pengunjung Museum”, Paper KNASTIK, 2013.

[3] Latius Hermawan dan Mochamad Hariadi, "Pemanfaatan Augmented Reality Sebagai Media Informasi Kampus Menggunakan Brosur", SENTIKA 2015, Yogyakarta, 2015.

[4] Muhammad Rifa'i dkk, "Penerapan Teknologi Augmented Reality Pada Aplikasi Katalog Rumah Berbasis Android", Prosiding SNATIF, Vol. 1, Hal. 267 274, 2014.

[5] Fadilah Fahrul Hardiansyah dan Yuliana Setiowati, "Augmented Reality Untuk Mengetahui Fasilitas Umum Berbasis Android", Jurnal Tugas Akhir, Jurusan Teknologi Informasi, Politeknik Elektronika Negeri Surabaya, Surabaya.Alfa Satyaputra dan Eva Maulina, Let's Build Your Android Apps with Android Studio. Jakarta: Elex Media Komputindo, 2016.

[6] Alfa Satyaputra dan Eva Maulina, Let's Build Your Android Apps with Android Studio. Jakarta: Elex Media Komputindo, 2016.

[7] Rickman Roedavan, Unity - Tutorial Game Engine. Bandung: Informatika, 2016.

[8] Eka Ardhianto, Wiwien Hadikurniawati dan Edy Winarno, "Augmented Reality Objek 3 Dimensi dengan Perangkat Artoolkit dan Blender", Jurnal Teknologi Informasi DINAMIK Vol. 17, No. 2, hal. 107-117, Jul, 2012.

[9] Yulius Eka Agung, Buku Pintar Pemrograman C\#. Yogyakarta: Mediakom, 2014. 